\title{
Method of modelling operation and maintenance processes in public transport systems using a certain class of stochastic processes
}

\author{
Bogdan L andowski ${ }^{1, *}$ \\ ${ }^{1}$ University of Science and Technology in Bydgoszcz, Faculty of Mechanical Engineering, AI. prof. \\ S. Kaliskiego 7, 85-796 Bydgoszcz, Poland
}

\begin{abstract}
The study presents a method for application of the theory $M$ arkov homogenous processes for modeling of the process of vehicle operational state changes characterized by exponential distribution of their duration time. A model of operation and maintenance of vehicles used in the research object has been developed. The research object is a city bus transport system situated in the analyzed agglomeration. Stochastic process $\{X(t), t \geq 0\}$ is a mathematical model of the process of operation and maintenance of public transport buses. The analyzed stochastic process $\{X(t), t \geq 0\}$ has a finite phase space $S, S=\left\{S_{1}, S_{2}, \ldots, S_{n}\right\}$. It was assumed that operation of the model is to be described by the homogeneous $M$ arkov process $\{X(t): t \in R+\}$ with a finite set of $S$ states. The states of the analyzed stochastic process correspond to the operational states distinguished for a bus. A hypothetical computing model was built in order to illustrate the discussion and present a method for application of the developed model. The parameters of the model were estimated based on the analysis of initial results of experimental tests conducted in a real bus transport system.
\end{abstract}

\section{Introduction}

Operation and maintenance of transport means is accompanied with different events whose effects have an impact on the processes of their operation and maintenance, as well as the economic effect worked out by the transport company. Technical objects used in a technical system undergo different operational states which make up the state space [1-3].

Assessment, analysis and prognosis of reliability and efficiency of transport systems are associated with mathematical modeling of technical object operation and maintenance processes characteristic of this class of systems [1-2, 4-6].

Operation efficiency of city transport systems and operated by them transport means can be analyzed in terms of economy and technology [1,7-9].

When analyzing operating costs of such systems it is necessary to take into consideration different cost categories including the costs involved in operation of subsystems whose task is to provide transport means with usability and those which deal with maintenance of the vehicles to keep them ready for use [2, 7-8]. Bus transport system operations involve many different costs including those involved in application of lubrication oils. In the case of relatively big bus combustion engines and a short time (coverage, service life) between successive oil changes this is a problem significant both in terms of economy and ecology [10-14]. Hence, many authors take up the subject of engine lubricants, the possibility of extending their operation time, and the models of transport

* Corresponding author: bl-sluzbowy@wp.pl, bogdan.landowski@utp.edu.pl 
means operation and maintenance processes often include the costs of lubrication oils as a separate cost category $[1,10-11]$.

It was assumed that the general mathematical model of the process of transport means operational states operated in city transport systems is stochastic process $\{X(t), t \geq 0\}$. The analyzed stochastic process $\{X(t), t \geq 0\}$ has a finite phase space $S, S=\left\{S_{1}, S_{2}, \ldots, S_{n}\right\}$.

One way to facilitate maintenance of appropriate level of reliability, availability and efficiency of public bus transport systems are to get familiar with the results of analysis of the operation and maintenance process models. This involves a necessity to provide a formalized description of transport means operation and maintenance processes. The most important is the one which involves changes of technical and operational states of objects and the processes connected with their operation and maintenance. These processes are of interrelated random character. Mathematical models of these processes are intrinsically simplified, therefore, practical conclusions provided by these models should be carefully formulated [1, 2, 5, 15-21].

Operational states of technical objects change in different sequences and their duration times like values of their other characteristics depend on decisions made by the decision makers $[1-3,5-6,9]$.

In order to determine the values of technical and economic measures for technical objects used in complex technical systems including city bus transport systems, such as reliability indices, it is necessary to obtain and process information on the subject of vehicle operation and maintenance. For this purpose, it is necessary to carry out experiments in a real system of technical object operation and maintenance [1-3, 7-8, 9, 15-16, 18-21].

Due to random character of the technical object sates, stochastic processes are used for modeling of operation and maintenance processes of these systems [1, 4-6, 8, 17, 22-24].

A natural model of operation and maintenance processes for many categories of technical objects is a random $\mathrm{X}(\mathrm{t})$ process with a finite state space $\mathrm{S}$ and a set of parameters $\mathrm{R}+$ (subset of real numbers $\geq 0$ ) [1]. Markov and semi Markov theory is used for mathematical modeling of the operation and maintenance processes of many technical objects [4-6, 9, 17, 22-24].

An analysis of models of operation and maintenance processes and systems allows to take up rational actions to improve reliability and safety of technical objects.

Both analytic and simulation methods are used to analyze the processes of an object state changes including those connected with occurrence of failure in random time moments. Literature provides examples of application of the homogeneous Markov and semi Markov processes as well as decision Markov and semi Markov processes in modeling of operational state changes $[1,3,5-6,9,22]$.

The study presents an example of application of the homogeneous Markov process theory for modeling of the process of state changes of the analyzed technical objects operated in a city bus transport system.

In technical sciences, stationary and homogeneous Markov processes are used, among others, for construction of models of reliability, inventory systems, risk analyses, spare part management and for modeling of technical object state changes [4, 9, 23-24].

Markov models are used, among others, for determination of the optimal number of spare objects $[1,17]$. In this area, a function of purpose in the form of minimization of a back-up system utilization costs and downtimes as well as the method of spare object utilization cost -benefit analysis are most commonly used for optimization.

Application of homogeneous Markov and semi Markov process in determination of technical object decision indices has been presented, among others, in work [9].

An analysis of the results of experimental test conducted in natural operation and maintenance conditions and tests of the operation and maintenance process models and 
systems can provide the basis for decision makers to take rational decisions that would increase efficiency of the system operations [1].

\section{Research object}

The research object is an operation and maintenance system of city transport buses in a selected urban agglomeration. According to the Central Statistical Office data of 31 December 2019, the population of the investigated town was about 110 thousand inhabitants.

The main goal of the considered socio-technical system is safe transport of passengers in assigned time in the qualitative and territorial scope. The analyzed objects are transport means used in the system. Transport tasks involve providing transport services along assigned traffic routes.

The net of the city bus transport encompasses an area inhabited by about 113 thousand people. The territorial scope of the transport net also covers seven neighboring locations, inhabited by about 3 thousand people. Only $2.56 \%$ of the population of the whole area where the analyzed transport means operate live beyond the town borders. The vehicles used in the research object, as in April 2019, provide transport services over twenty regular traffic lines, four express lines and one, the so called, special line (connection with a municipal cemetery).

$\mathrm{O}$ weekdays, depending on the time of day, the number of vehicles in use ranges from 10 in late evening hours (about 23) to 48 in the morning rush hours.

As on 01.01.2020, the research object used 68 buses. Buses of Solaris Urbino 10 prevail in the research object. There are also: Solaris Urbino 12, Solaris Urbino 12 Hybrid and Solaris Urbino 12 Electric.

The unit of measure for transport task accomplishment is the so called 'VKT -vehicle kilometers travelled" denoting coverage of a distance of one kilometer along an assigned route scheduled in a transport plan or in connection with accomplishment of other transport tasks.

The tasks accomplished in the first half year of 2019 were 1.8 million 'VKT' including: town lines about 1.75 million 'VKT', suburban lines outside the town borders, about 32 thousand 'VKT' and the so called commissioned transports and others, about 21 thousand "VTK'.

During the whole 2019 transport tasks were accomplished for particular transport routes in the total number of 3.7 million 'VKT'. 3.6 million 'VKT' were covered for city transports, whereas, about 65 thousand for the so called ordered transports and the remaining ones covered about 48 thousand 'VKT'.

For the purpose of this study, the research object was divided into two subsystems. The first one is called an executive subsystem responsible for accomplishment of its major tasks, consisting of elementary subsystems of the type <operator-vehicle $>$, which carry out passenger transports. The second subsystem is responsible for maintenance of transport means and is made up of subsystems that provide diagnostics, servicing, repairs and other services for the elementary subsystems of the executive system [1].

The executive system consists of an operating subsystem containing $\mathrm{n}$ basic elements necessary to carry out a task and a reserve system containing k spare elements [1].

Direct accomplishment of tasks is the responsibility of the executive subsystem containing elementary subsystems of the type $\mathrm{H}-\mathrm{E}>\mathrm{TO}$ (H-human Env. - technical object), in which a human is coupled with a technical object through a series structure. Reliability of the operated technical objects is kept at an appropriate level through services provided by the maintenance subsystem. In the analyzed transport system, a damaged bus is referred to the maintenance subsystem, where it undergoes maintenance. If available at a given moment, spare vehicles are directed to the executive subsystem where they replace 
the damaged vehicles. Since the buses sustain damage on a random basis, reports come to the maintenance system randomly as well. After a repair, a serviceable vehicle goes to the executive subsystem or to an internal parking of the bus garage. The bus is stored on an internal parking when the number of serviceable vehicles is sufficient to provide a full range of transport services. The time of the vehicle servicing is of random character [1].

Further, the vehicles used in the analyzed research object are assumed to be homogeneous in terms of the assumptions accepted in the model.

\section{Assumptions of the operation and maintenance process}

It was assumed that, from the point of view of the study goal, separate subsets of homogeneous objects can be distinguished in the set of technical objects operated in the research object. It means that within the analyzed subsets, the objects have the same characteristics in terms of their operation and maintenance. Further considerations are related to a subset of such objects [1].

Stochastic process $\{\mathrm{X}(\mathrm{t}), \mathrm{t} \geq 0\}$ is a mathematical model of bus operation and maintenance. The analyzed stochastic process $\{\mathrm{X}(\mathrm{t}), \mathrm{t} \geq 0\}$ has a finite phase space $\mathrm{S}$, $\mathrm{S}=\left\{\mathrm{S}_{1}, \mathrm{~S}_{2}, \ldots, \mathrm{S}_{\mathrm{n}}\right\}$. It was assumed that operation of the model is described by the homogeneous Markov process $\left\{\mathrm{X}(\mathrm{t}): \mathrm{t} \in \mathrm{R}_{+}\right\}$with a finite set of $\mathrm{S}$ states. The states of the analyzed stochastic process correspond to the operational states distinguished for a bus operation. When using the homogeneous Markov process for mathematical modeling of the operation and maintenance process, an assumption was accepted that from the perspective of the study goal, the process well represents the real operation and maintenance of technical objects.

It is possible to determine probabilities $P_{i}(t), i=1,2, \ldots, n$, of technical objects' being in the distinguished operational states $S_{i}$ by using the Markov theory of processes. For this purpose, A. N. Kołmogorov differential equation system of the form:

$$
\mathbf{P}^{\prime}(t)=\mathbf{P}(t) \Lambda,
$$

needs to be solved,

where:

$$
\begin{aligned}
& \mathbf{P}^{\prime}(t) \text { - column vector consisting of derivatives } \mathbf{P}_{\mathrm{i}}{ }^{\prime}(\mathrm{t}), \\
& \mathbf{P}(t) \text { - probability vector } \mathbf{P}_{\mathrm{i}}(\mathrm{t}), \\
& \Lambda \quad \text { - matrix of the process state changes, } \\
& t \quad \text { - time, } t \geq 0 .
\end{aligned}
$$

For illustrative purposes, the following bus operational state changes were analyzed:

$\mathrm{S}_{1} \quad$ - operational state - a state in which a bus and its operator accomplish their transport tasks;

$\mathrm{S}_{2} \quad$ - maintenance state in the subsystem of maintenance;

$\mathrm{S}_{3} \quad$ - servicing state within the bus transport system - a state in which a bus is serviced by the so called, technical emergency service;

$\mathrm{S}_{4} \quad$ - standby state when a bus is waiting for service.

Possible transitions between the states have been determined. Matrix of $\{\mathrm{X}(\mathrm{t}), \mathrm{t} \geq 0\}$ process intensity change was determined for the distinguished operational states.

Probability that in time $t$, process $\{X(t), t \geq 0\}$ will be in $S_{i} \in S$ state, was denoted by $\mathrm{P}_{\mathrm{i}}(\mathrm{t})=\mathrm{P}\left\{\mathrm{X}(\mathrm{t})=\mathrm{S}_{\mathrm{i}}\right\}, \mathrm{i}=1,2, \ldots, 4$. State $\mathrm{S}_{1}$, was assumed to be the initial state of $\mathrm{X}(\mathrm{t})$, eg, that the initial distribution of the analyzed process has the following form:

$$
\begin{aligned}
& P\left\{X(0)=S_{1}\right\}=1, \\
& P\left\{X(0)=S_{i}\right\}=0 \quad \text { dla } i \neq 1, S_{i} \in S, i=\{1,2,3,4\} .
\end{aligned}
$$


Intensities $\lambda_{i, j}, i, j=1,2,3,4$ of $\{X(t), t \geq 0\}$ process state transformations from $S_{i} \in S$ into $S_{j} \in S$ were included in transition intensity matrix $\Lambda$ :

$$
\Lambda=\left|\begin{array}{cccc}
-\lambda_{11} & \lambda_{12} & \lambda_{13} & \lambda_{14} \\
0 & -\lambda_{22} & 0 & \lambda_{24} \\
\lambda_{31} & \lambda_{32} & -\lambda_{33} & 0 \\
\lambda_{41} & 0 & 0 & -\lambda_{44}
\end{array}\right|
$$

Denotations were introduced:

$$
\begin{gathered}
\lambda_{11}=\lambda_{12}+\lambda_{13}+\lambda_{14} \\
\lambda_{22}=\lambda_{24} \\
\lambda_{33}=\lambda_{31}+\lambda_{32} \\
\lambda_{44}=\lambda_{41}
\end{gathered}
$$
form:

Transition intensity matrix $\Lambda$ allows to develop a system of differential equations of the

$$
\left\{\begin{array}{l}
\left.\mathrm{P}_{1} q t\right)=-\lambda_{11} \mathrm{P}_{1}(t)+\lambda_{31} \mathrm{P}_{3}(t)+\lambda_{41} \mathrm{P}_{4}(t) \\
\mathrm{P}_{2} \mathrm{q}(t)=\lambda_{12} \mathrm{P}_{1}(t)-\lambda_{22} \mathrm{P}_{2}(t)+\lambda_{32} \mathrm{P}_{3}(t) \\
\mathrm{P}_{3} \mathrm{q}(t)=\lambda_{13} \mathrm{P}_{1}(t)-\lambda_{33} \mathrm{P}_{3}(t) \\
\mathrm{P}_{4} \mathrm{q}(t)=\lambda_{14} \mathrm{P}_{1}(t)+\lambda_{24} \mathrm{P}_{2}(t)-\lambda_{44} \mathrm{P}_{4}(t)
\end{array}\right.
$$

To provide equation system (9) with an unequivocal solution, it is necessary to accept initial conditions defined by dependencies (2) and (3).

For the analyzed $\{\mathrm{X}(\mathrm{t}), \mathrm{t} \geq 0\}$ process there is a stationary distribution which does not depend on the process initial distribution:

$$
\operatorname{limp}_{t \rightarrow \infty}(t)=p_{i}^{*}
$$

Stationary probabilities $p_{i}^{*}$ satisfy the equation system:

$$
\left\{\begin{array}{l}
\sum_{i=1}^{n} \mathrm{p}_{\mathrm{i}}^{*} \lambda_{\mathrm{ij}}=0, \quad \mathrm{dla} \quad \mathrm{j}=1,2,3, \ldots, \mathrm{n} \\
\sum_{i=1}^{n} \mathrm{p}_{\mathrm{i}}^{*}=1
\end{array}\right.
$$

Determined matrix $\Lambda$ and a normalizing condition, equation system (11) can be written as follows: 


$$
\left\{\begin{array}{l}
-\lambda_{11} p_{1}^{*}+\lambda_{31} p_{3}^{*}+\lambda_{41} p_{4}^{*}=0 \\
\lambda_{12} p_{1}^{*}-\lambda_{22} p_{2}^{*}+\lambda_{32} p_{3}^{*}+\lambda_{42} p_{4}^{*}=0 \\
\lambda_{13} p_{1}^{*}-\lambda_{33} p_{3}^{*}=0 \\
p_{1}^{*}+p_{2}^{*}+p_{3}^{*}+p_{4}^{*}=1
\end{array}\right.
$$

Experimental tests were performed in a real operation and maintenance system in order to estimate the values of the model parameters.

An analysis of duration times of the distinguished operational states was performed as part of the initial experimental tests conducted in a real city bus transport system. The tests were carried out in natural conditions of bus transport operation and maintenance by the method of passive experiment.

\section{Calculation example}

A calculation example was provided to illustrate the discussion. The calculations were performed for different values of the model parameters representing changes of a controlling function in the research object. An impact the analyzed events on the process was prognosed.

Selected results of two calculation variants have been presented. Calculations performed for the model parameter values, estimated for the existing system, corresponding to its state prior to the effects of simulated events, were marked as model 'M1'.

The calculation variant, marked as „M2" model, reflects the impact of reduction in the so called number of 'secondary' failures and a change in the service process organization. A secondary failure is referred to as a failure of the same vehicle unit. To put it simply, simulation of a decrease in the number of this type of failures involved changing the value of elements of the state change matrix of Markov chain imbedded in $\mathrm{X}(\mathrm{t})$. The simulation of changes of the servicing process organization involved changing the expected value of random variables denoting duration times of states, respectively $S_{2}$ and $S_{3}$.

Change of the expected value of a random variable denoting the duration time of services provided both at the service stations and by the technical emergency units can also be the effect of the impact of other factors, eg, change of organization, conditions of maintenance service provision, increase in the number of operators of technical emergency services, etc. [1].

Table 1. Basic input data used for calculations.

\begin{tabular}{|c|c|c|c|c|c|c|c|}
\hline & $\lambda_{12}$ & $\lambda_{13}$ & $\lambda_{14}$ & $\lambda_{24}$ & $\lambda_{31}$ & $\lambda_{32}$ & $\lambda_{41}$ \\
\hline $\mathbf{M 1}$ & 0,00638 & 0,01276 & 0,04477 & 0,34375 & 0,73337 & 0,18337 & 0,24882 \\
\hline $\mathbf{M 2}$ & 0,004074 & 0,005044 & 0,041322 & 0,538932 & 1,293301 & 0,323301 & 0,2425 \\
\hline
\end{tabular}

The basic data used for calculations are presented in table 1. Table 2 shows the results of boundary probability calculation results for particular calculation variants.

The results of the model tests confirm the model expected reaction to the values of its parameter changes. It confirms correctness of the calculations and usefulness of the model for initial prognoses of the analyzed system state after a change of the analyzed factor impact levels on the system. 
Table 2. Results of calculations for stationary probabilities.

\begin{tabular}{|c|c|c|c|c|}
\hline & $\mathrm{p}_{1}^{*}$ & $\mathrm{p}_{2}^{*}$ & $\mathrm{p}_{3}^{*}$ & $\mathrm{p}_{4}^{*}$ \\
\hline $\mathbf{M 1}$ & 0,796348449 & 0,020693028 & 0,011084284 & 0,17187424 \\
\hline $\mathbf{M 2}$ & 0,830626178 & 0,007833746 & 0,002591657 & 0,158948418 \\
\hline
\end{tabular}

\section{Conclusions}

The aim of the study is to show the possibilities of using the Markov process theory for modeling of the process of transport means operation and maintenance in city bus transport systems.

When using the homogeneous Markov process for mathematical modeling of the process of operation and maintenance it was assumed that, from the point of view of the study goal, the process well reflects the real operation and maintenance processes.

An analysis of the study results shows that the developed model is sensitive to the input parameter value change.

The proposed method allows, depending on the needs and goals, to construct models with an adequate level of specificity and identified state space. It seems that an analysis of the results of tests of models built for different parameter values, being decision variants, can facilitate making rational decisions about the system operation.

Such an analysis enables, among others, an initial assessment of technical and organizational aspects of vehicle operation and maintenance and economic aspects of transport services, which can allow to take rational actions in order to improve operation of an engineering system.

\section{References}

1. B. Landowski, M. Woropay, A. Neubauer, Controlling reliability in the transport systems (Sterowanie niezawodnościa $w$ systemach transportowych), Library of Maintenance Problems, Bydgoszcz-Radom 2004, Maintenance Technology Institute (2004)

2. B. Landowski, D. Perczyński, Ł. Muślewski, P. Kolber, Economic aspects of a city transport means purchase. Proceedings of 58th International Conference of Machine Design Departments - ICMD 2017, Publisher: Czech University of Life Sciences Prague, Czech Republic, pp. 194-199 (2017)

3. B. Landowski, Ł. Muślewski, Numerical simulation of stochastic process as a model of technical object state changes. Engineering Mechanics 2018 Proceedings, Vol 24 Book Series: Engineering Mechanics, 24nd International Conference, may 14 - 17, 2018, Svratka, Czech Republic, Book of full texts, Institute of Theoretical and Appiled Mechanics of the Czech Academy of Sciences, Prague, pp. 485-488 (2018)

4. N. Buslenko, W. Kalasznikov, I. Kovalenko, Theory of complex systems (Teoria systemów złożonych), PWN, Warszawa (1979)

5. J. Girtler, Application of theory of semi-Markov processes to determining distribution of probabilistic process of marine accidents resulting from collision of ships, Polish Maritime Research 2014 no 1 (81), vol. 24, pp. 9-13, (2014)

6. B. Landowski, Ł. Muślewski, Decision model of an operation and maintenance process of city buses, Proceedings of 58th International Conference of Machine Design Departments - ICMD 2017, Publisher: Czech University of Life Sciences Prague, Czech Republic, pp. 188-193 (2017)

7. Ł. Muślewski, L. Knopik, B. Landowski, O. Polishchuk, Analysis of assessment criteria for selected systems of transport means operation, MATEC Web of Conferences 182, 02003 (2018), 17th International Conference Diagnostics of Machines and Vehicles, pp.1-10 (2018) 
8. B. Landowski, Ł. Muślewski, M. Pająk, O. Polishchuk, Method for initial assessment of unit costs of public city transport means operation, MATEC Web of Conferences 182, 01010 (2018), 17th International Conference Diagnostics of Machines and Vehicles, pp.1-7 (2018)

9. B. Landowski, D. Perczyński, P. Kolber, Ł. Muślewski, An example of Markov model of technical objects maintenance process. Engineering Mechanics 2016, 22nd International Conference, may 9 - 12, 2016, Svratka, Czech Republic, Book of full texts, Institute of Thermomechanics Academy of Sciences of the Czech Republic, pp. 346-349 (2016)

10. B. Landowski, M. Baran, Analysis of selected results of engine oil tests, MATEC Web of Conferences 302, 01010 (2019), 18th International Conference Diagnostics of Machines and Vehicles, pp.1-7 (2019)

11. B. Landowski, M. Baran, Analysis of changes in the value of selected lubricant characteristics during use, MATEC Web of Conferences 302, 01009 (2019), 18th International Conference Diagnostics of Machines and Vehicles, pp.1-8 (2019)

12. M. Markiewicz, Ł. Muślewski, M. Pająk, Impact Of Biocomponent Additive To Diesel Oil On Values Of Elected Functional Parameters Of Transport Means, Polish Journal Of Environmental Studies, Vol. 29, (2020)

13. M. Markiewicz, Ł. Muślewski, Survey performance and emission parameters of diesel engine powered by diesel oil and fatty acid methyl esters using fuzzy logic techniques, Fuel, Vol. 277, (2020)

14. M. Markiewicz, Ł. Muślewski, The Impact Of Powering An Engine With Fuels From Renewable Energy Sources Including Its Software Modification On A Drive Unit Performance Parameters, Sustainability, Vol. 11, (2019)

15. P. Kolber, D. Perczyński, K. Peszyński, B. Landowski, Efficiency testing of thermoelectric cooling cell based on peltier module. Engineering Mechanics 2018 Proceedings, Vol 24 Book Series: Engineering Mechanics, 24nd International Conference, may 14 - 17, 2018, Svratka, Czech Republic, Book of full texts, Institute of Theoretical and Appiled Mechanics of the Czech Academy of Sciences, Prague, pp. 381-384 (2018)

16. P. Kolber, D. Perczyński, B. Landowski, S. Wawrzyniak, The control system of the stepper motor motion with positioning accuracy verification. Engineering Mechanics 2016 Proceedings, Vol 22 Book Series: Engineering Mechanics, 22nd International Conference, may 9 - 12, 2016, Svratka, Czech Republic, Book of full texts, Institute of Thermomechanics Academy of Sciences of the Czech Republic, pp. 298-301 (2016)

17. Hamoud G. A.: Use of Markov Models in Assessing Spare Transformer Requirements for Distribution Stations, in IEEE Transactions on Power Systems, vol. 27, no. 2, pp. 1098-1105, May (2012)

18. T. Kałaczyński, M. Łukasiewicz, J. Musiał, R. Polasik, M. Szczutkowski, N. Dluhunovych, J. Wilczarska, T. Kasprowicz, Analysis of the diagnostic potential research thermovision in the technical state of combustion engine injectors assessment. Engineering Mechanics 2018, 24nd International Conference, 1805-8248, 1417.05.2018 Svratka, Czech Republic (2018)

19. A. Pavarekha, D. Kapski, A. Voytik, M. Łukasiewicz, The choice of parameters hydrodynamic retarder brake with increased power capacity. 17th International Conference Diagnostics of Machines and Vehicles. MATEC Web Conf. Volume $182(2018)$

20. M. Łukasiewicz, T. Kalaczynski, J. Musial, J. Shalapko, Diagnostics of buggy vehicle transmission gearbox technical state based on modal vibrations, Journal of Vibroengineering, Volume 16, Issue 6, pp. 3137-3145 (2014) 
21. V. Martynyuk, O. Eromenko, J. Boiko, T. Kałaczyński, Diagnostics of supercapacitors, 17th International Conference Diagnostics of Machines and Vehicles, Matec Web of Conferences 2018, 182, pp. 1-10 (2018)

22. M. L. Puterman, Markov decision processes, John Wiley, New York (1994)

23. Hamoud G. A., Lee L., Faried S. O.: Spare Assessment of Distribution Power Transformers using Two Markov Models, 2019 IEEE Power \& Energy Society General Meeting (PESGM), Atlanta, GA, USA, pp. 1-5 (2019)

24. K. Tee, E. Ekpiwhre, Z. Yi, Degradation modelling and life expectancy using Markov chain model for carriageway, Int J Qual Reliab Manag 2018, 35, 1268-1288 (2018) 